\title{
Video Tracking based Rehabilitation Exercise Monitoring Tool for Osteoarthritis
}

\author{
Nideshika Ellepola \\ Sri Lanka Institute of Information Technology \\ Sri Lanka
}

\author{
G.D.S. Prasad Wimalaratne \\ University of Colombo School of Computing \\ Sri Lanka
}

\begin{abstract}
Physical therapy exercise monitoring and human body motion is two disciplines with high level of research interest. Physical therapy is the treatment of disease, injury, or deformity by physical methods. Physical therapy exercises are mainly used by health care professionals to rehabilitate patients. Physical therapy rehabilitation suffers from less monitoring of patient movements in home environment. The study is carried out considering the physical therapy exercises for knee Osteoarthritis. Osteoarthritis is a joint disease that mostly affects cartilage. There are many physical therapy exercises that can be taken as treatments for the infections. This research paper presents the design, development and testing of a prototype application suitable for home rehabilitation process. The main objective of this thesis to create a methodology to evaluate the rehabilitation exercises performed at home. The prototype tool is implemented and tested with Microsoft Kinect Xbox-360 sensor as the motion detection device. The experimental results prove the accuracy and the correctness of the application.
\end{abstract}

\section{Keywords}

Physical Therapy, Kinect Xbox - 360, Osteoarthritis, Rehabilitation Exercise

\section{INTRODUCTION}

Applications of human motion detection have made a vast improvement with the introduction of novel technologies. Healthcare is one such discipline where researchers try to apply various methods of human motion detection techniques to automate the activities. Over the past years many applications were developed to evaluate physical therapy exercise movements of patients.

Physiotherapy exercises generally carried out under the supervision of a qualified physiotherapist or physiotherapist assistance. They are the qualified professionals with the knowledge to direct the patient to the correct method of exercise needed to be performed. Due to lack of quality physical therapy professionals the patients cannot always seeks the help of them. In most situations patients observe and learn the exercises explained by the physiotherapist at the clinic. Then the patients repeat the same exercise at home by recalling the memory. Physiotherapist provides a printed hand out to the patient with the steps involved for the particular exercise [1]. However, patients might perform wrong in repeating the exercises with the absence of proper guidance. Physiotherapist too lacks the facility to monitor and correct those malpractices of the patient's actions. This is one of the main difficulties in practicing home based rehabilitation. The research is focused on physical therapy exercise practiced by patients deceased by osteoarthritis. Different types of exercises are used in rehabilitating patients suffering from osteoarthritis. These are applied to either knee or hand depending on the deceased organ of the body. Hand exercises have a high involvement of fingers and writs movements. Knee exercises are divided as standing exercises and sitting exercises. Most of the knee exercises involve the movements of the lower body while keeping the upper body at one posture.

The research paper highlights the previous work on the specific domain, the methodology followed, results of the system and the discussion.

\section{LITERATURE REVIEW}

This section describes the background content addressed in the research. Arthritis is a complex family of musculoskeletal disorders. Arthritis consists of more than 100 different types and conditions that destroy joints, bones, muscles, cartilage and other connective tissues [2]. Among those Osteoarthritis (OA) is one of the oldest and most common forms of arthritis affected by millions of people around the world [3]. Osteoarthritis is a joint disease that mostly affects cartilage. Cartilage is the part of the joint that cushions the ends of the bones and allows easy movement of joints. The cartilage, which acts as a shock absorber, will gradually wear away in some areas. As the cartilage becomes damaged tendons and ligaments become stretched, causing pain. Eventually the bones may rub against each other causing very severe pain.

Osteoarthritis can be affected to different organs of the body. The most common are the knee and hand. Varieties of treatment methods as used to recover from OA. They are exercise, weight control, joint protection, physical and occupational therapy and medications. Physical therapy is the treatment of disease, injury, or deformity by physical methods such as massage, heat treatment, and exercise, also known as physiotherapy. Physiotherapy exercises are important part in the recovery of patients or clients with musculoskeletal disorders. Physical therapy is a common method of treatment used in patients with OA.

Schonauer et al. [4] developed a serious game to help in the rehabilitation process of patients suffering chronic pain the neck and lower back. They track the patient's movements using lotraker which is a passive marker-based motion capture system. Bruke et al. [5] created two small games focused on upper-limb rehabilitation. The camera tracks colored markers the patient wears or holds with his hand. Another system was developed by Brudea et al [6] using infrared tracking. The patient wears a low friction forearm support that has some switched and the infrared LEDs.

Lower cost tracking devices greatly decreases the overall price of such rehabilitation systems that are designed for use away from the clinic. For instance, several groups are working with webcams to track patient's hand or objects using passive markers. Main drawback in this method is the patient's clothes can interfere with the tracking of passive color markers if similar colors are present. 
Even though good results have been obtained by these groups there are some issues that limit or difficult the use of the systems at home. Some of these methods include wearing devices to the patient's body. This cannot be done at home because the patient will have to buy this equipment and it will cost a lot. Also, not all the patients are technically literate to use all these tracking devices and will face many difficulties. Therefore, most of these methods have technical difficulties and they are good for laboratory environments. Changes in the room's lighting can also decrease the trackers accuracy or make it stop working. Another disadvantage of using a single camera is that only $2 \mathrm{D}$ tracking is possible limiting rehabilitation exercises to just planar movements. In addition, when active markers or Wii remotes are used the patient has to hold or wear a device. This can be difficult and uncomfortable. Furthermore, low operational patients might not be able to grab the devices or open their hands to hold the trackers.

Instead of using highly technical devices some of the commercially available devices can be used in the rehabilitation applications. Acosta [7], [8] developed a game to rehabilitate the upper limb of stroke patients using Microsoft Kinect and physiotherapy exercises. "Institute of West Health" has built an application named "Reflexion Rehabilitation Measurement Tool (RMT)" [9], with collaboration with MIT and Microsoft to monitor patients remotely to ensure they're exercising properly.

Pasqual Vitale [10] has presented work on understanding the precision and accuracy of the Kinect for detecting therapeutic movements in rehabilitation. He tried to understand the threshold of the Kinect device in combination with rehabilitation exercises. He has designed an evaluation plan to grade the exercise performed in to three categories as "Excellent", "Good" and "Bad". Pasqual presented his work by considering three knee exercises and related movements. His experimental results describe the algorithm developed evaluate the knee exercises had a $50 \%$ effectiveness for the Excellent case. The overall judgment of this work presents that Kinect device has very good accuracy and precision.

Hondori, H. And Khademi, M. have conducted a literature study and proved that many rehabilitation engineers prefer using Kinect sensor in their systems due to the accuracy of the motion capture compared to the other methods. Moreover, the authors has suggested that the developers should consider the occlusion and noise in skeleton tracking using Kinect [11].

W. Zhao et. al has developed A Kinect-based rehabilitation exercise monitoring and guidance system incorporating virtual reality techniques to demonstrate the movements of the patients. The main contribution of the system was to introduce a rulebased approach to real-time exercise quality assessments. They also emphasis on the fact that most of the available systems the physio therapist is unable to monitor the exercising movements of the patient. Hence it is difficult to provide a correct feedback to the patient [12].

\section{METHODOLOGY}

The system was developed based on prototype methodology. The system comprises of three main modules. Figure 2 illustrates the modules.

Template generator is one of the main components of the architectural design. The main function of this component is to create a template of an exercise by capturing the limbs and joints involved in the exercise. First the template generator captures the required skeleton details of the exercise performed. When required the physiotherapist can perform the exercise with the correct steps using a motion tracking device. The skeleton and joint details captured are used for further processing. Skeleton data required depends on the type of the exercise performed. Knee bend exercise consists of two steps as shown in Figure 1 [13]
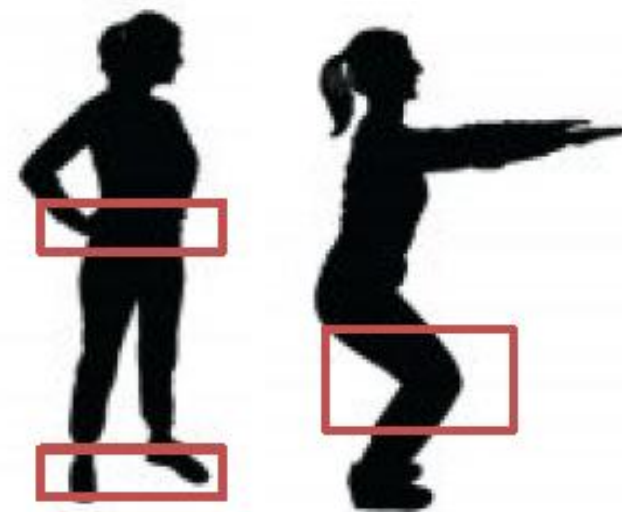

Fig 1: Knee bend - Step 01 and Step 02

Once the joint details information is collected the next phase is to perform the required calculations. The calculations needed to perform depend on the type of the exercise. During exercise evaluation it is important to check each limb of the body is in the correct position. While performing the exercise placement of limbs can change the result of the exercise being performed. When the exercise template is created, it is necessary to measure the exact orientation of each limb of the body. For an example, how far the legs needed to be placed during the exercise. 


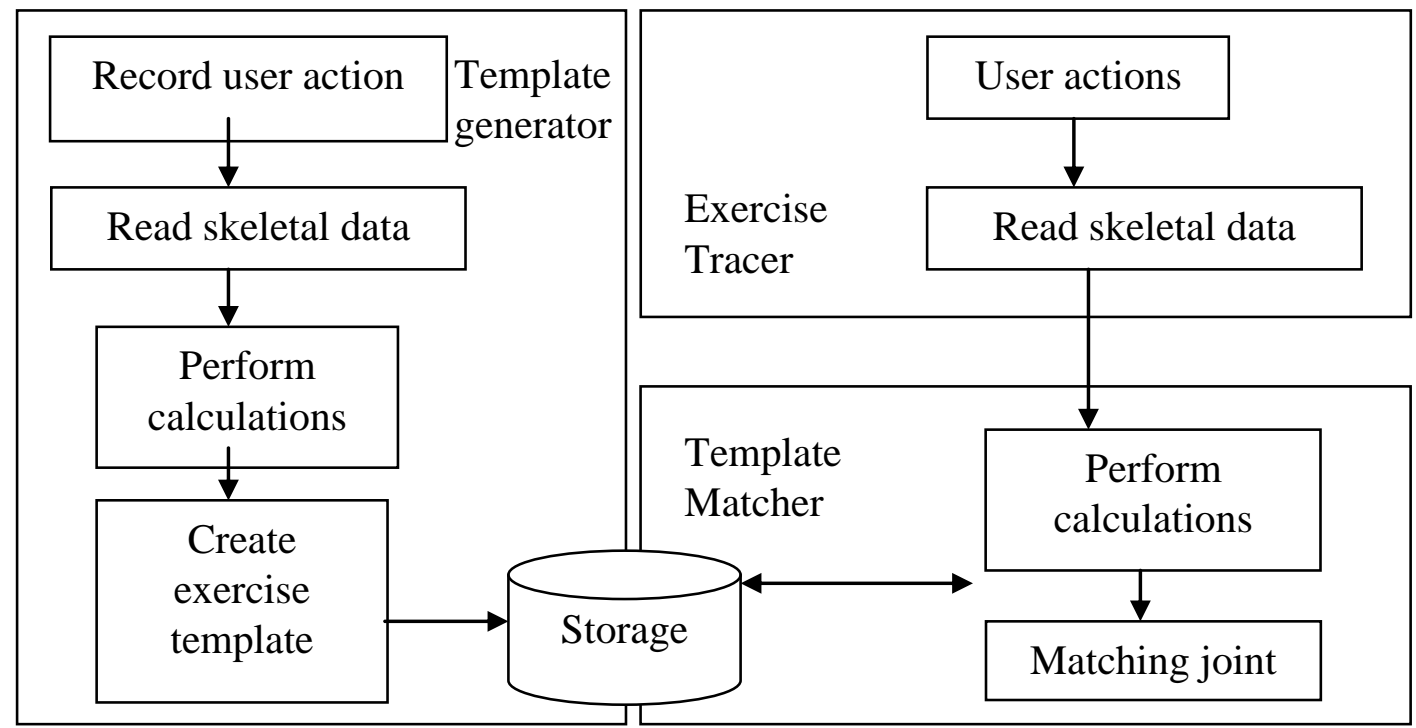

Fig 2: Architectural diagram

As the first step of joint distance calculation the exact position of the interested joint should be read. The read position will be represented by $\mathrm{X}, \mathrm{Y}$ and $\mathrm{Z}$ coordinate values in the $3 \mathrm{D}$ space. These coordinate values will be used to calculate how far each limb is positioned. For example, if the exercise requires moving one leg up while keeping the other leg on the ground. The position of the leg raised up can be measured with respect to the position of the leg on the ground. The two leg positions can be represented in a coordinate system as shown below.

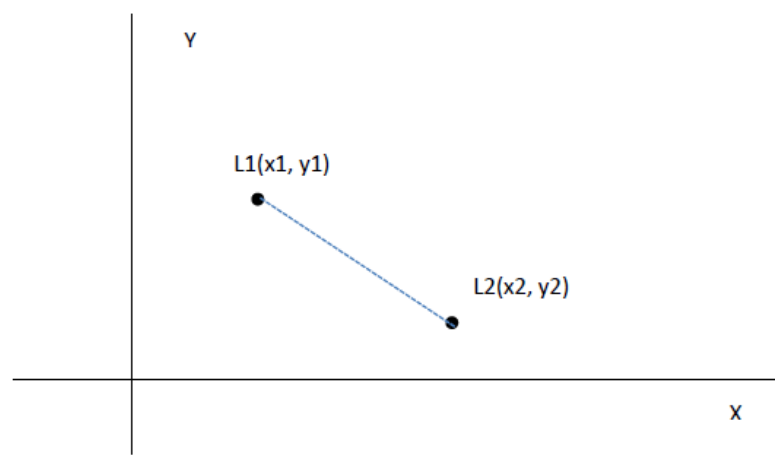

Fig 3: Calculating the distance between two points

Distance between the two legs (positions L1 and L2) can be calculated using the Equation 1.

$\mathrm{d}(\mathrm{L} 1, \mathrm{~L} 2)=\sqrt{(x 1-x 2)^{2}+(y 1-y 2)^{2}}$

Using this method any joints distance can be calculated with respect to another joint.

Another important value calculated is the angle between joints. The angles between various joints play an importance in exercise evaluation. Some exercises are evaluated by considering the angles between the joints. If the exercise is monitored by a physiotherapist they have the opportunity to check the angle while exercise is performed. The required values can be guessed by naked eye. When the process is automated it is necessary to calculate the joint angles properly to evaluate the correctness. For an example, Knee bends exercise: the knee should not have bend more than 90 degrees as shown in Figure 4.

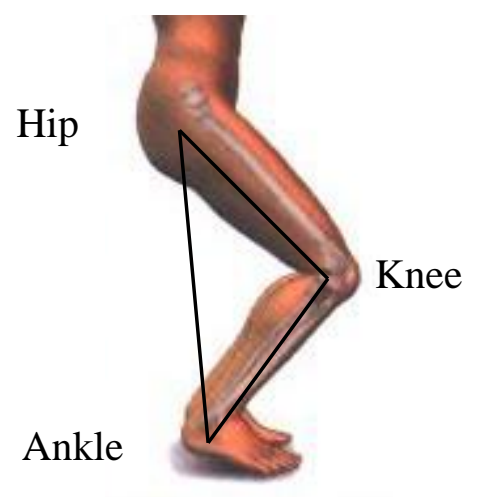

Fig 4: Joints related to knee bend exercise

The angle between any joint is calculated using lows of trigonometry. First create a triangle combining the joints surrounding the interested angle.

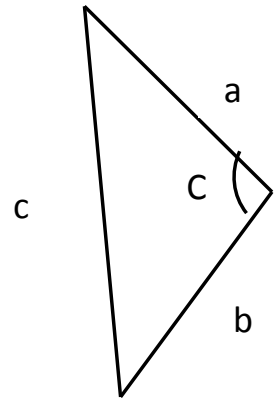

Fig 5: Joints forming a triangle

For the knee bend exercise, it is hip, knee and the foot. Read the positions of these joints. The lengths of the three sides $a, b$ and $\mathrm{c}$ (see Figure 5) are calculated from the three joint positions. Then use the Law of Cosine equation to calculate the angle of $\mathrm{C}$ [14].

Law of Cosines

$c^{2}=a^{2}+b^{2}-2 a b \cos C$

From equation (2) we can derive $\mathrm{C}$ as;

$C=\cos ^{-1}\left(\frac{a^{2}+b^{2}-c^{2}}{2 a b}\right)$ 
Once all the necessary calculations are done these values should be stored as an exercise template. One of the main finding of the research is a XML definition of the exercises. Exercise definition must capture all the key poses of an exercise. All the exercise definitions are stored in XML format which is read when the patient performs the exercise. Coordinates of the interested joints for the selected exercise (see Figure 5,6) is collected by reading the skeleton information. The calculated distances between the joints and the angles between the joints along with the respective $\mathrm{X}, \mathrm{Y}, \mathrm{Z}$ coordinate values are written in to the XML file. The exercise definition must include both key frames recording as well as transitional movements between these key frames. Parameters such as 3D points, joint angles and the distance between joints are calculated in the application and the XML file is created. Figure 6 shows the structure of the XML file.

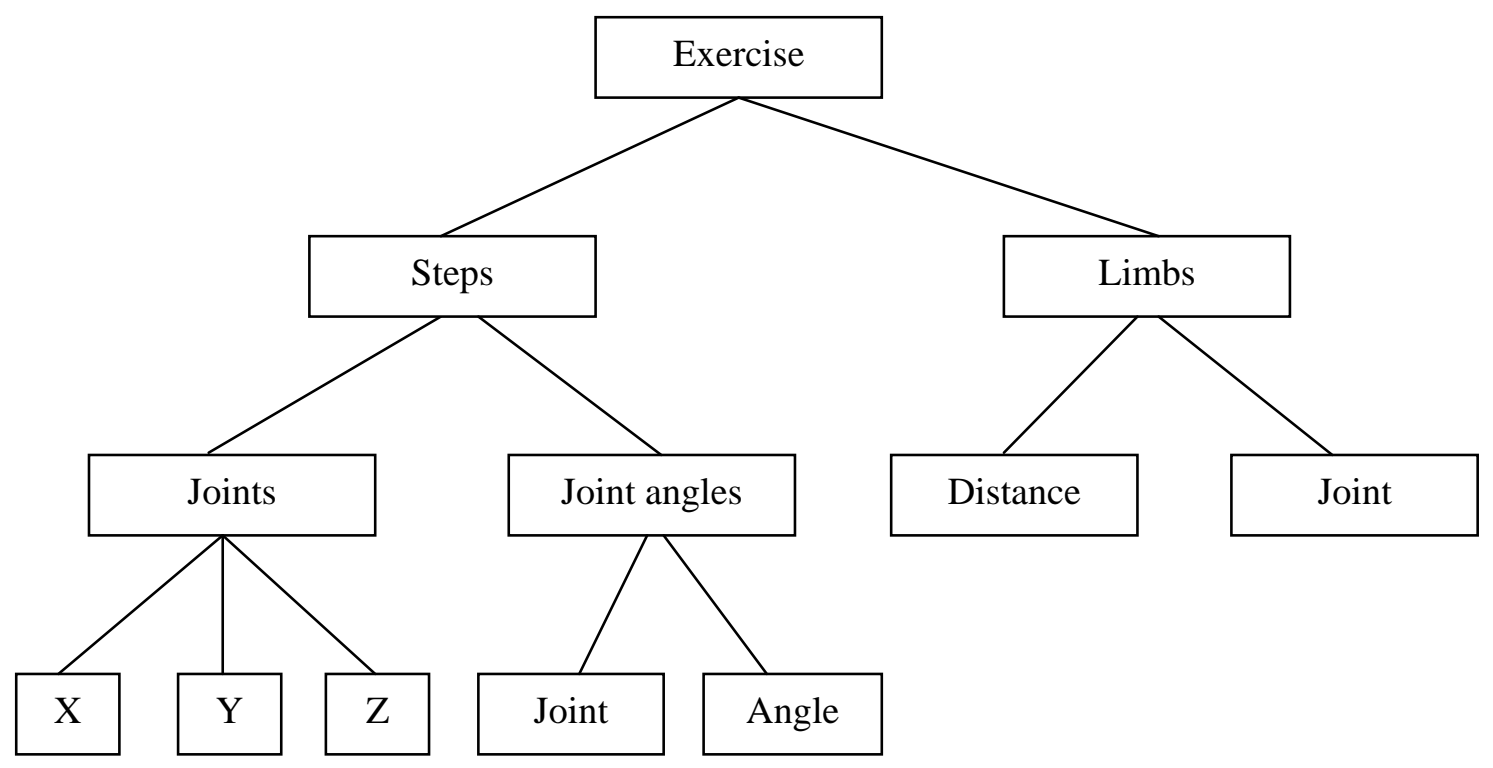

Fig 6: XML File Structure

After exercise templates are stored, patients can perform the exercises using the application. When the patient performs the exercise the exercise tracker reads all the required skeleton information of pose of each step of the exercise. These real-time data readings are used for the calculations. Template matcher takes the values passed by exercise tracker to measure the correctness of the exercise performed by the patient. Like in the template creation process the joint position values are subjected to calculations. Before performing any evaluation on the exercise being performed real time required distance values and angle values are calculated. Once the calculations are completed it is required to be compared with the stored exercise template. First it is necessary to read the XML definition stored for the exercise. Then should identify which pose of the exercise being compared. Once the correct pose is selected both stored values and the real time values are compared. If any divergences of the values detected, the user is notified. Exercise tracking and template matcher runs in parallel to measure the correctness of poses in each step of the exercise. For an example, if knee bend exercise is considered, the angle behind both knees should not be less than 90 degrees. If the angle value falls below this number, the user is notified by displaying the joint area with errors in different color. This process continues until all the steps are properly checked against the saved template and necessary feedback is given to the user. The user is able to see the corrections suggested by during exercise evaluation to correct the incorrect poses of each step.

The system comprises of two applications as follows

- Exercise Generator - The backend application where the exercise template generated.

- $\quad$ Exercise Evaluator - The application which can be used by the patients to evaluate their exercises.

The main interface of the backend application is shown in Figure 7. This interface allows designers and therapist to directly perform the exercises in a step by step manner and outputs the corresponding XML file. 


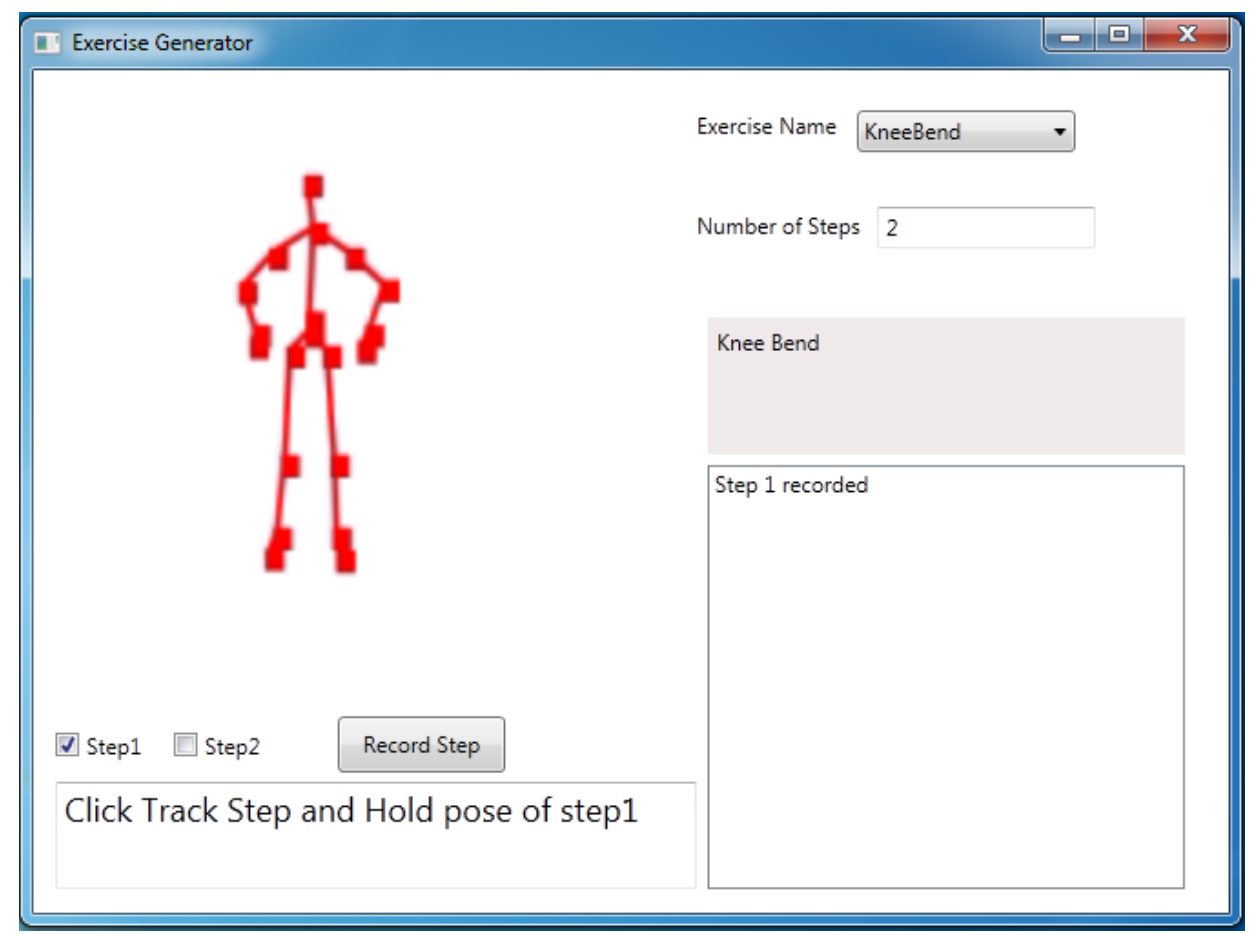

Fig 7: Template Creator Interface

The application first takes some global measurements at the beginning. This is done so that exercises can be scaled properly to the patient's hip center when the exercise is being captured. The name of the exercise and the number of steps is entered in to the interface before the user starts performing the exercise. Providing the name of the exercise and the number of steps is very critical because distance calculations and reading joint positions depends on the type of the exercise. After providing this information to the application the user can perform the exercise step by step until all the steps are completed
The frontend application is used by patients who perform the exercise. Figure 8 depicted the main interface of the front-end application. Same as the backend application it is required to provide the name of the exercises at the beginning. The reason is same patient may be assign several exercises at the same time. Depending on the exercise being performed the template matching algorithm should compare the movements with the exercise of the same exercise template. Another reason is the calculations performed and the joint information read depends on the exercise selected.

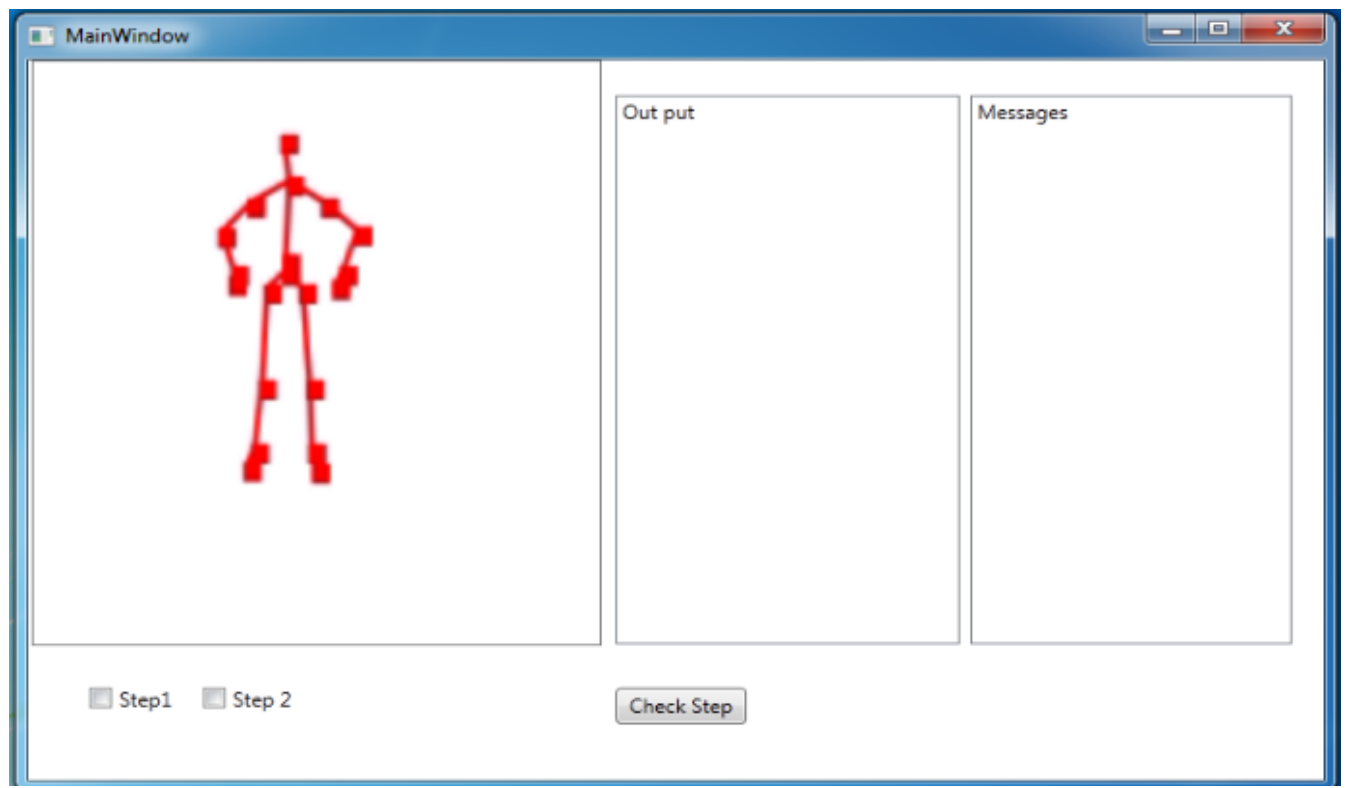

Fig 8: Exercise tracker interface

\section{RESULTS AND DISCUSSION}

The accuracy and the correctness of the methodology described are evaluated using a prototype application created. The Kinect device is kept two feet above the ground and two feet away from the tester. A computer with Windows 7 operating system is used to run the application. A qualified physiotherapist is consulted to select the best physical therapy exercise to proceed with the evaluation of the methodology and the application. Considering the limitations of the Kinect sensor and the physiotherapist's ideas following exercises are selected to start with the system. All the selected exercises are for the knee. 
The selected set of knee rehabilitation exercises are;

1. Knee bends

2. March

3. Kick forward

In all kinds of exercises there are common movements.

The spine must always stay in a vertical position, because the entire spine must be straight including the head. This results the head and spine must be perpendicular to the floor. The position of the hips must always be in horizontal position, so the line between right hip and left hip should always be horizontal. All movements of the selected exercises have the same joints involved: knee, ankles, hips and spine. It is impossible to a human to be stay at the same pose without any jitters. In this application the sensor will be always stationary in one place while the patient is moving the limbs performing exercises. There is a marginal error in the values read by Kinect sensor. The reason for this is there can be jitter/ noise movements of the user while performing the exercise. Therefore, it is important leave a marginal error value. Therefore, different threshold values were used to check the correctness of the calculations. Table 1, Table 2 and Table 3 shows the threshold values considered in two settings for knee bends exercise. The best threshold value is selected for fine tune the application and user evaluation phase.

Table 1: Knee bends exercise: Knee angle threshold values

\begin{tabular}{|c|c|c|c|c|}
\hline & & \multicolumn{3}{|c|}{ Knee angle(in degrees) } \\
\hline \multirow[t]{3}{*}{$\begin{array}{l}\text { Setting } \\
01\end{array}$} & & $\begin{array}{l}\begin{array}{l}\text { Lower } \\
\text { threshold }\end{array} \\
-10\end{array}$ & $\begin{array}{l}\text { Correct } \\
\text { angle }\end{array}$ & $\begin{array}{l}\text { Upper } \\
\text { threshold } \\
+10\end{array}$ \\
\hline & Step 01 & 170 & 180 & 190 \\
\hline & Step 02 & $\begin{array}{l}\text { Angle } \\
\text { cannot be } \\
\text { less than } 90\end{array}$ & 90 & 110 \\
\hline \multirow[t]{3}{*}{$\begin{array}{l}\text { Setting } \\
02\end{array}$} & & $\begin{array}{l}\text { Lower } \\
\text { threshold } \\
-20\end{array}$ & $\begin{array}{l}\text { Correct } \\
\text { angle }\end{array}$ & $\begin{array}{l}\text { Upper } \\
\text { threshold } \\
+20\end{array}$ \\
\hline & Step 01 & 160 & 180 & 200 \\
\hline & Step 02 & $\begin{array}{l}\text { Angle } \\
\text { cannot be } \\
\text { less than } 90\end{array}$ & 90 & 120 \\
\hline
\end{tabular}

Table 2: Knee bends exercise: Foot distance threshold values

\begin{tabular}{|l|l|l|l|l|}
\hline & \multicolumn{4}{|c|}{$\begin{array}{l}\text { Distance between left foot and right foot } \\
\text { (in meters) }\end{array}$} \\
\hline $\begin{array}{l}\text { Setting } \\
01\end{array}$ & & $\begin{array}{l}\text { Lower } \\
\text { threshold } \\
-0.2\end{array}$ & $\begin{array}{l}\text { Correct } \\
\text { distance }\end{array}$ & $\begin{array}{l}\text { Upper } \\
\text { threshold } \\
+0.2\end{array}$ \\
\cline { 2 - 5 } & $\begin{array}{l}\text { Step 01 } \\
\text { \& } \\
02\end{array}$ & 0.1048 & 0.3048 & 0.5048 \\
\hline $\begin{array}{l}\text { Setting } \\
02\end{array}$ & & $\begin{array}{l}\text { Lower } \\
\text { threshold } \\
-0.3\end{array}$ & $\begin{array}{l}\text { Correct } \\
\text { distance }\end{array}$ & $\begin{array}{l}\text { Upper } \\
\text { threshold } \\
+0.3\end{array}$ \\
\cline { 2 - 5 } & $\begin{array}{l}\text { Step 01 } \\
\text { and }\end{array}$ & 0.048 & 0.3048 & 0.6048 \\
& Step 02 & & & \\
\hline
\end{tabular}

Table 3: Knee bends exercise: Distance between hands and hip joints threshold values

\begin{tabular}{|c|c|c|c|c|}
\hline 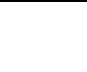 & & $\begin{array}{l}\text { Distance } \\
\text { right hand }\end{array}$ & $\begin{array}{l}\text { n left har } \\
\text { hip (in m }\end{array}$ & hip left and \\
\hline \multirow[t]{2}{*}{$\begin{array}{l}\text { Setting } \\
01\end{array}$} & & $\begin{array}{l}\text { Lower } \\
\text { threshold } \\
-0.2\end{array}$ & $\begin{array}{l}\text { Correct } \\
\text { distance }\end{array}$ & $\begin{array}{l}\text { Upper } \\
\text { threshold } \\
+0.2\end{array}$ \\
\hline & $\begin{array}{l}\begin{array}{l}\text { Step } 01 \\
\text { and }\end{array} \\
\text { Step } 02\end{array}$ & -0.2 & 0 & 0.2 \\
\hline \multirow[t]{2}{*}{$\begin{array}{l}\text { Setting } \\
02\end{array}$} & & $\begin{array}{l}\begin{array}{l}\text { Lower } \\
\text { threshold }\end{array} \\
-0.3\end{array}$ & $\begin{array}{l}\text { Correct } \\
\text { distance }\end{array}$ & $\begin{array}{l}\text { Upper } \\
\text { threshold } \\
+0.3\end{array}$ \\
\hline & $\begin{array}{l}\text { Step } 01 \\
\text { and } \\
\text { Step } 02\end{array}$ & -0.3 & 0 & +0.3 \\
\hline
\end{tabular}

Five rounds for each criterion are carried out and the Table 4 and Table 5 show the outcome of these rounds. The best setting is selected by taking the average of individual criterion. Result was calculated using the following equation.

$$
\text { Result }=\frac{\text { Rounds Passed }}{\text { Total Number of rounds }} \times 100
$$

Table 4: Setting 1 result

\begin{tabular}{|l|l|l|l|l|l|}
\hline $\begin{array}{l}\text { Setti } \\
\text { ng 1 }\end{array}$ & Criteria & $\begin{array}{l}\text { Total } \\
\text { Rounds }\end{array}$ & Pass & Fail & Result \\
\hline & $\begin{array}{l}\text { Knee } \\
\text { angle }\end{array}$ & 5 & 4 & 1 & $80 \%$ \\
\cline { 2 - 6 } & $\begin{array}{l}\text { Distance } \\
\text { between } \\
\text { left foot } \\
\text { and right } \\
\text { foot }\end{array}$ & 5 & 5 & 0 & $100 \%$ \\
\cline { 2 - 6 } & $\begin{array}{l}\text { Distance } \\
\text { between } \\
\text { left hand }- \\
\text { hip left }\end{array}$ & 5 & 4 & 1 & $80 \%$ \\
\hline
\end{tabular}




\begin{tabular}{|l|l|l|l|l|l|}
\hline & $\begin{array}{l}\text { and right } \\
\text { hand-right } \\
\text { hip }\end{array}$ & & & & \\
\hline
\end{tabular}

Table 5: Setting 2 results

\begin{tabular}{|l|l|l|l|l|l|}
\hline $\begin{array}{l}\text { Setti } \\
\text { ng 2 }\end{array}$ & criteria & $\begin{array}{l}\text { Total } \\
\text { Rounds }\end{array}$ & Pass & Fail & Result \\
\hline & $\begin{array}{l}\text { Knee } \\
\text { angle }\end{array}$ & 5 & 2 & 3 & $40 \%$ \\
\cline { 2 - 6 } & $\begin{array}{l}\text { Distance } \\
\text { between } \\
\text { left foot } \\
\text { and right } \\
\text { foot 5 }\end{array}$ & $\begin{array}{l}\text { Distance } \\
\text { between } \\
\text { left hand }- \\
\text { hip left } \\
\text { and right } \\
\text { hand-right } \\
\text { hip 5 }\end{array}$ & 3 & 2 & $60 \%$ \\
\hline
\end{tabular}

According to the results shown in Table 4 and Table 5 the Setting 1 produced a better accuracy compared to Setting 2. Based on the results, threshold values of Setting 1 were selected and proceeded to Phase two.

The fine-tuned backend and front-end applications were used for the user evaluation. During the user evaluation the system is tested with three users by varying the distance between user and the camera. Most of the osteoarthritis patients are above 40 years old. Hence the speed of doing the exercise varies from patient to patient.

It is very critical to test the accuracy of the application for varying speed of exercising. Test cases are chosen to have a variation of the height, age. Table 6 summarizes system evaluation criteria.

Table 6: User evaluation criteria

\begin{tabular}{|l|l|}
\hline Criteria & Number rounds \\
\hline $\begin{array}{l}\text { Accuracy based on selected } \\
\text { exercise }\end{array}$ & 10 \\
\hline $\begin{array}{l}\text { Speed of exercising-based } \\
\text { evaluation }\end{array}$ & 10 \\
\hline Effect of patients age & 5 \\
\hline
\end{tabular}

Five users have been selected and performed the knee bend exercise. The two steps were tested separately for number of testing rounds.

Table 7: Accuracy based on the selected exercise

\begin{tabular}{|l|l|l|l|l|}
\hline User & Rounds & Pass & Fail & result \\
\hline 1 & 10 & 5 & 5 & $50 \%$ \\
\hline 2 & 10 & 8 & 2 & $80 \%$ \\
\hline 3 & 10 & 9 & 1 & $90 \%$ \\
\hline 4 & 10 & 7 & 3 & $70 \%$ \\
\hline 5 & 10 & 8 & 2 & $80 \%$ \\
\hline
\end{tabular}

During this testing five different users perform the knee bend exercise for 10 rounds each. Averages of all the user results are calculated and obtain the accuracy of the application. The individual results are shown in Table 7. The test reported $80 \%$ of individual accuracy and $74 \%$ of average accuracy. According to these readings, it can conclude that based on the exercise selected the system is capable of identifying the exercise steps performed by the user.

One of the challenges faced in implementation is the inability to predict the speed of the exercise performed. Most of the osteoarthritis falls into elderly patient group, hence the speed of each patient performs the exercise varies. In order to test the performance of the system with varying speed of exercising the same exercise is tested considering the number of frames used to complete each step (i.e. 5, 20 and 30).

Table 8: Accuracy rate based on speed of exercising

\begin{tabular}{|l|l|l|}
\hline Number of Frames & $\begin{array}{l}\text { Step } \\
\text { Accuracy }\end{array}$ & Step2 Accuracy \\
\hline 5 & $40 \%$ & $50 \%$ \\
\hline 10 & $50 \%$ & $55 \%$ \\
\hline 20 & $90 \%$ & $87 \%$ \\
\hline 30 & $85 \%$ & $80 \%$ \\
\hline
\end{tabular}

According to the results in Table 8 it indicates that most of the exercise steps are not properly identified when the exercise completion frames are very low. Starting from frame number 10 onwards almost all the exercise steps shows high accuracy rate reflecting that exercise matching algorithm is capable of recognizing the poses even with varying speeds. Hence the system is capable of evaluating exercises performed at varying speeds.

\section{LIMITATIONS AND FUTURE WORK}

There were several limitations where the study was bounded on. One limitation is that the Kinect sensor should be placed at the correct height. The patient should be standing keeping the correct distance from the Kinect sensor. The placement and the distance can have effects on the accuracy of the readings and the calculations. Moreover the patient should stand in front of the device's visibility range.

This works opens up large number of avenues for future works and improvements also since this field has an extended area. In order to improve the quality of the application and its judgment it is possible to add more rules in the evaluation of the movements. Furthermore, this application can be extended by incorporating exercises with varying number of steps. Another new research could be to use objects for improvement feedback from Kinect detection. As an example, to use a real physical object useful for rehabilitation like a chair or a stick. Apart from that hand exercises and sitting mode exercises can be addressed as new research work. Hand exercises heavily involve movements of fingers and rotation of wrist. Sitting mode exercises have knee movements. Finger tracking and sitting mode human motion tracking are two research areas with demand. These two types of exercises contain different movements and limitations of calculations.

\section{ACKNOWLEDGEMENT}

Special thank is extended to Dr. Dr. G.D.S.P. Wimalaratne for all the guidance given throughout the research. 


\section{REFERENCES}

[1] K. Terry. (2012, Jan.). InformationWeek: Physical Therapy App Uses Microsoft Kinect. [Online]. Available: http://www.informationweek.com/mobile/physicaltherapy-app-uses-microsoft-kinect/d/d-id/1106586?

[2] Arthritis Foundation, Disease Center: Osteoarthritis. [Online]. Available:www.arthritis.org/conditionstreatments/disease-center/osteoarthritis/

[3] Mayo Clinic, Osteoarthritis, Mayo Clinic staff. [Online]. Available:http://www.mayoclinic.com/health/osteoarthritis /DS00019

[4] C. Schonauer, T. Pintaric, H. Kaufmann, S. Jansen Kosterink, and M.Vollenbroek-Hutten, "Chronic Pain Rehabilitation with a Serious GameUsing Multimodal Input," in Virtual Rehabilitation (ICVR), 2011International Conference on, 2011, pp. 1-8.

[5] J. W. Burke, M. D. J. McNeill, D. K. Charles, P. J. Morrow, J. H. Crosbie, and S. M. McDonough, "Augmented Reality Games for Upper-Limb StrokeRehabilitation," in Games and Virtual Worlds for Serious Applications (VSGAMES),2010 Second International Conference on, 2010, pp. 75-78.

[6] G. C. Burdea, D. Cioi, J. Martin, D. Fensterheim, and M. Holenski, "TheRutgers Arm II Rehabilitation System-A Feasibility Study," Neural Systems and Rehabilitation Engineering, IEEE Transactions on, vol. 18, pp. $505514,2010$.

[7] Isaac Pastor Acosta, "Upper limb Rehabilitation of Stroke Patients using Kinect and Computer Games", in IEEE
Transactions on Neural Systems and Rehabilitation Engineering, 2012

[8] Isaac Pastor Acosta, "Upper limb Rehabilitation of Stroke Patients using Kinect and Computer Games", M.S. thesis, School of Computing University of Utah, 2012

[9] Tech Trends, Reflexion Rehabilitation Measurement Tool (RMT). [Online]. Available: http://hpectechtrends.wordpress.com/2012/12/28/ reflexion-rehabilitation-measurement-tool-rmt/

[10] Pasquale Vitale. "Evaluation and Measurements of Kinect Movement Detection in Physical Therapy", M.S. thesis, University of Skövde, 2012

[11] H. Hondori and M. Khademi, "A Review on Technical and Clinical Impact of Microsoft Kinect on Physical Therapy and Rehabilitation", Journal of Medical Engineering, vol. 2014, no. 846514, p. 16, 2014.

[12] W. Zhao, H. Feng, R. Lun, D. Espy and M. Reinthal, "A Kinect-based rehabilitation exercise monitoring and guidance system", in 2014 IEEE 5th International Conference on Software Engineering and Service Science, Beijing, China, 2014, pp. 762-765.

[13] 123RF, Illustration - girls exercising silhouettes. [Online]. Available: http://www.123rf.com/photo_8009426_girlsexercising-silhouettes.html.

[14] Jarrett Webb, James Ashley,"Beginning Kinect Programming with the Microsoft Kinect SDK",1st ed. Spring Street, New York: Springer Science Business Media, 2012.

[15] 